\title{
Analytical Hierarchy Process Decision Support System (AHP-DSS) for Trenchless Technology
}

\author{
Mohamed Salah $^{\mathrm{a}}$, Soliman Abu Samrab ${ }^{\mathrm{b}}$, Ossama Hosny ${ }^{\mathrm{a}}$ \\ ${ }^{a}$ Construction Engineering Department, The American University in Cairo, Egypt \\ ${ }^{\mathrm{b}}$ Department of Building, Civil and Environmental Engineering (BCEE), Concordia University, Canada \\ Email: msahmed@aucegypt.edu, solimanamr_8@aucegypt.edu, ohosny@aucegypt.edu
}

\begin{abstract}
Among the increasing complexities and surface development, underground utilities installation, renewal and repair remain one of the most challenging projects worldwide. In addition, the crucial need for a minimal surface disruption is what even makes it more thought provoking for contractors/specialists to maintain. That is why, trenchless technology has been an economical choice for many contractors/specialists, especially in urban areas, to guarantee less restoration costs, social, and environmental impact and higher accuracy with less time compared to the open cut and cover method. This paper aims to introduce a framework, utilizing a fully automated Analytical Hierarchy Process engine, which supports the contractors in their selection for the most appropriate trenchless method, taking the project characteristics and site conditions into consideration. The framework features through four different modules as follows: (1) Input Module where the user enters the project attributes through the AHP-DSS user interface. (2) Central Database Module that contains the considered trenchless methods, project attributes limits \& their weights and trenchless methods \& their scores. Analytical Hierarchical-based Engine that runs simultaneously with the central database module to provide the user with the most suitable construction method. (4) Trenchless Technology Method Module that shows the most suitable method that suits the pre-defined user inputs. Spreadsheet modelling has been used for developing the Analytical Hierarchal Process Decision-Support System (AHP-DSS). A case study composed of 20 projects with various characteristics and conditions has been used for validating and verifying the model. The results showed a percentage of error less than $10 \%$ compared to the actual executed results
\end{abstract}

Keywords - AHP, Decision support system; Modeling, Trenchless technology

\section{Introduction}

Underground utilities e.g. (pipes, cables, conduits, force mains, etc.) can be executed using traditional methods, known as open cut convention methods where a trench is excavated using excavator or labour then the required utility is placed followed by backfilling. Open cut method requires cautious contractors to excavate and maneuverer around existing under-ground utilities in order to avoid damaging any existing underground utility; consequently, it may lead to slower production rates. In addition, they might be more expensive compared to trenchless methods in congested areas, especially when considering the restoration costs i.e. costs of restoring back the sidewalks, landscapes, road pavement, etc. [1].

Moreover, open cut method proved to result in dramatically higher social costs as it leads to traffic disruption, noise, and damage of existing underground utilities in many occasions [2]. Ariaratnam et al [3] has developed sustainability index "USIR", which considers three factors "costs, social impact and environmental impact" to measure how sustainable open cut and trenchless methods are. The results showed that open cut has higher USIR i.e. (higher adverse impact economically, socially and environmentally) compared to the other trenchless methods in the study.

On the other hand, trenchless methods according to North America Society of Trenchless Technology (NASTT) is defined as "a family of methods, materials, and equipment capable of being used for the installation of new or replacement or rehabilitation of existing underground infrastructure with minimal disruption to surface, traffic, business, and other activities" which makes it more suitable in congested areas. However, 
some contractors and decision makers are not familiar with the trenchless methods, when it shall be used, and which method suits the project being approached. Careful planning and selection of the appropriate trenchless method is crucial to aid the stakeholders in taking their decisions and reduce any risks stemming from the inappropriate trenchless method selections.

\section{Literature Review}

Hastak and Gokhale [4] developed AUTOCOP that aids the user in selecting between pipe ramming, pipe bursting and open cut method through the application of an AHP-based engine through evaluating groups of criteria and sub-criteria with respect to the knowledge based preference of the user and the project specific situations.

Ueki et al [5] developed a decision tool that utilizes a rule-based expert system for selecting between open cut method and microtunneling methods (Slurry and Earth Pressure Balance "EPB"). The decision was based on depth of invert below the ground, pipe diameter, driving length, ground water level, site conditions, soil information and boulders existence and size.

Baik et al [6] developed a DSS that selects the most appropriate horizontal directional drilling method for a certain project based on pipe diameter, depth of installation, driving length, soil type, pipe material, pullback load, machine selection, and productivity.

Chung et al [7] further modified Ueki's model by including cost, duration estimation and the selection of shaft's construction method.

Bottero and Peila [8] developed a DSS for open cut and microtunneling methods using AHP based on construction time, construction cost, and environmental problems.

As highlighted above, it was recognized that most of the previous research was focusing on certain types of trenchless methods and disregarded the others such as; auger boring, pipe ramming, open face TBM, etc. In addition, some researchers did not vitalize the impact of crucial attributes such as; social and/or environmental surroundings, required level of accuracy, and type of utility installed e.g. (sewer, cables, etc.).

\section{Objective}

This paper aims to develop a computerized trenchless technology decision support system that aids decisionmakers in selecting the most appropriate trenchless method based on various project characteristics and conditions (soil condition, depth, diameter...etc.) and recognizing the social, environmental attributes, accuracy level required and type of utility installed.

\section{Methodology}

There are various methods and approaches for developing a decision support system. However, Analytical Hierarchy Process "AHP" was used in this research. Saaty developed AHP in 1980 where: it structures the decision problem in various levels, corresponding to the situation understanding, objectives, criterion and sub-criterion, and solution alternatives. Through this structure, the decision maker is able to focus on a smaller set of decisions. The proposed model was performed using both MS-Visual Basic and MS- Excel.

The model considers seven different trenchless methods in addition to the open cut method, which are as follows: (1) Horizontal Auger Boring; (2) Pipe Ramming; (3) Mini horizontal directional drilling (Mini HDD); (4) Maxi HDD; (5) Pipe Jacking Open face TBM; (6) Earth Pressure Balance (EPB) microtunneling and (7) Slurry microtunneling. On the other hand, the model considers various attributes as follows: (1) Project type; (2) Depth of installation; (3) Soil type; (4) Driving length; (5) Pipe diameter; (6) Pipe material; (7) Social consideration; (8) Environmental consideration; (9) Utility type installed; (10) Accuracy required; (11) Ground water table level (12) Boulders size (if any).

\section{AHP-DSS Framework}

The AHP-DSS framework features through four consecutive modules as follows: (1) Input Module (2) Central database; (3) AHP engine and (4) Trenchless technology interface. Figure 1 displays the framework of the model and its modules.

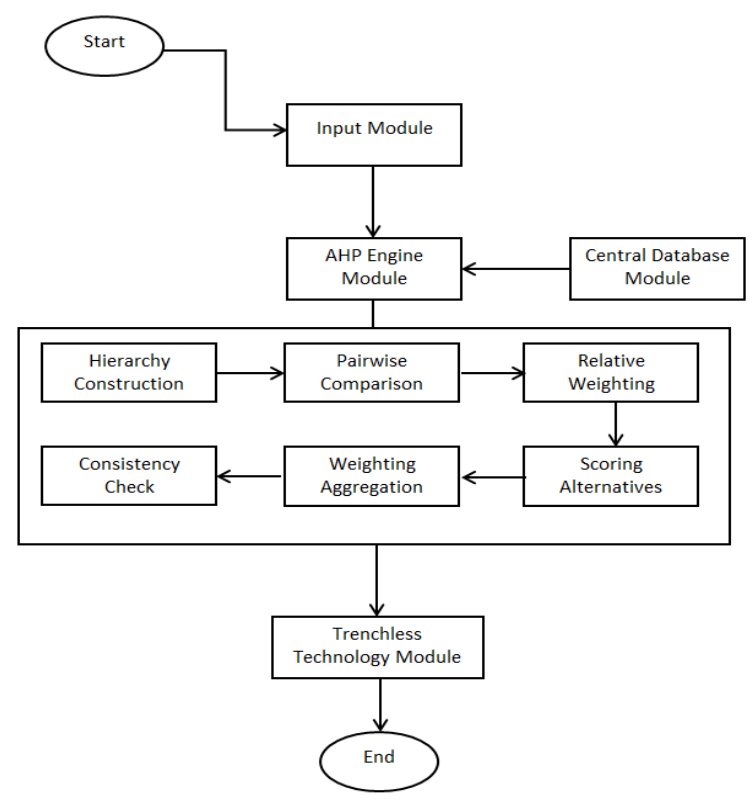

Figure 1: AHP-DSS Framework 


\subsection{Module 1: Inputs Module}

The user enters the project attributes through the AHP-DSS user interface. The model placed list of options to some attributes where the user has to select one of them. This is applied to pipe material, soil type, boulders availability, social \& environmental issues, accuracy required \& type of utility installed.

\subsection{Module 2: Central database}

The central database module consists of three submodules as follows: (1) Trenchless methods in which the methods, considered in this research, are defined; (2) Attributes limits and weights where; the attributes weights and limits are defined; and (3) Methods vs attributes scoring where; the methods are scored against the attributes. The data was gathered from industry experts and previous researches and papers (Baik et al [5] and Allouche [9]).

\subsection{Module 3: AHP Engine}

AHP engine runs through consecutive modules as follows: (1) Hierarchy construction, (2) Pair wise comparison, (3) Relative Weight, (4) Scoring alternatives, (5) Aggregation of weights and, (6) Consistency check.

\subsubsection{Hierarchy Construction}

Involves decomposing the complexity where; decision factors are organized in a hierarchy-type structure. As shown in Figure 2, the primary goal of the problem "Selection of Trenchless technology" occupies the highest level of the structure, followed by "sets of attributes" that are the factors affecting the selection of trenchless methods Then, a third level is creating "Sub factors" that explain the attributes.

Finally, the feasible alternatives evaluation takes place at the lowest AHP hierarchy level.

\subsubsection{Pair Wise Comparison}

Once the hierarchy is constructed, comparing the attributes needs to be conducted. Hence, after, the following questions need to be answered, which attribute is more important or has greater influence on the attribute one level higher in the hierarchy. What is the intensity of that importance?
Saaty [10] translated the intensity assessment into numbers as shown in table 1 . It should be noted that the pairwise comparison method is perhaps the cornerstone of the entire AHP philosophy, as it allows the user to systematically determine the intensities interrelationships of a practically great-unlimited number of decision factors.

Table 1: Random Index (Saaty [10])

\begin{tabular}{|l|l|l|}
\hline $\begin{array}{l}\text { Relative } \\
\text { Intensity }\end{array}$ & Definition & Explanation \\
\hline $\mathbf{1}$ & Of equal value & $\begin{array}{l}\text { Two requirements are of } \\
\text { equal value. }\end{array}$ \\
$\mathbf{3}$ & $\begin{array}{l}\text { Slightly morerience slightly favours } \\
\text { value } \\
\text { one requirement over } \\
\text { another. }\end{array}$ \\
$\mathbf{5}$ & $\begin{array}{l}\text { Essential or strong } \\
\text { value }\end{array}$ & $\begin{array}{l}\text { Experience strongly favours } \\
\text { one requirement over } \\
\text { another. } \\
\text { A requirement is strongly } \\
\text { favored and its dominance is } \\
\text { demonstrated in practice. } \\
\text { The evidence favouring one } \\
\text { over another is of the } \\
\text { highest possible order of } \\
\text { affirmation. } \\
\text { When compromise is } \\
\text { needed. }\end{array}$ \\
$\mathbf{2 , 4 , 6 , 8}$ & $\begin{array}{l}\text { Very strong value } \\
\text { Intermediate } \\
\text { values between } \\
\text { two adjacent } \\
\text { judgments }\end{array}$ & \begin{tabular}{l}
$|l|$ \\
\hline
\end{tabular} \\
\hline
\end{tabular}




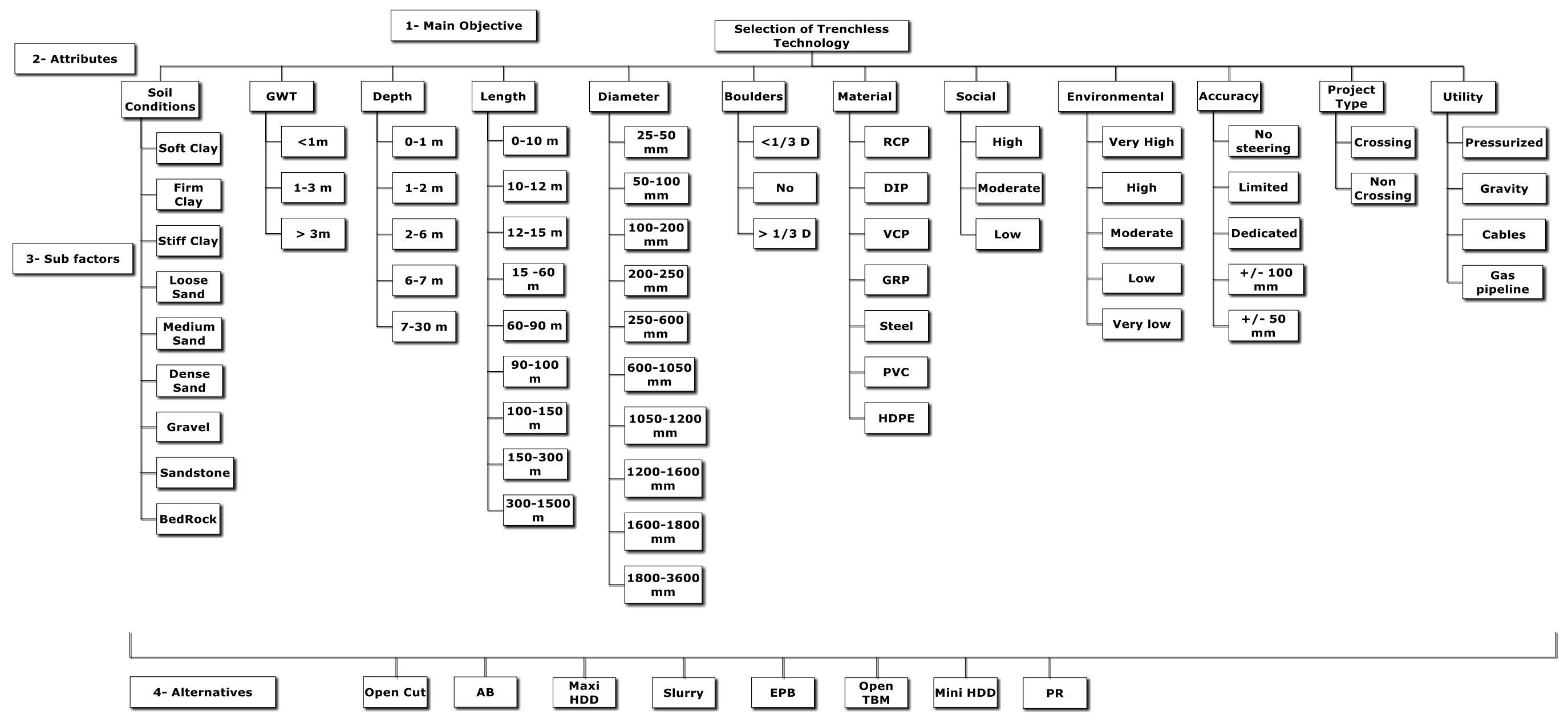

Figure 2: Hierarchy Construction 


\subsubsection{Relative Weight}

Relative weights are calculated for the attributes called "Eigen Vector" or priority weight. This can be achieved by using "Column Normalization" or "Nth Root Method". In this paper, Nth root method was used where; it is calculated by multiplying the $n$ elements in each row by each other and taking the nth root to form a new column vector. Then, the priority vector $(\mathrm{W})$ is calculated by normalizing the column vector. The example in table 2 illustrates the calculations procedure for a pairwise comparison.

Table 2: Priority Weight Calculation

\begin{tabular}{|l|l|l|l|l|l|l|}
\hline & A & B & C & Product & $\begin{array}{l}\text { Nth } \\
\text { root }\end{array}$ & $\begin{array}{l}\text { Priority } \\
\text { Vector } \\
(\mathrm{W})\end{array}$ \\
\hline A & 1 & 3 & 1 & 3 & 1.44 & 0.44 \\
\hline B & 0.333 & 1 & 0.5 & 0.166 & 0.55 & 0.18 \\
\hline C & 1 & 2 & 1 & 2 & 1.26 & 0.38 \\
\hline
\end{tabular}

\subsubsection{Scoring Alternatives}

In this part, the same methodology, adopted for attributes relative weight calculation, is used for scoring the alternatives. It determines the extent to which each trenchless method satisfies each sub-factor, e.g. to what extent EPB work in soft clay or to what extent auger boring works with driving length more than $120 \mathrm{~m}$, etc.

\subsubsection{Aggregation of Weights}

Results obtained from the two previous phases; the pairwise comparisons and the scoring of the alternatives, are aggregated to produce a quantitative measure of the benefits, and offered by each trenchless method, as per the equation below.

$T T_{\text {Score }}=\sum\left(A_{s} * R W_{c}\right)$

Where;

$T T_{\text {Score }}$ : Is the trenchless method quantitative measure.

$A_{s}$ : The score of each alternative with respect to each attribute.

$R W_{c}$ : The relative weight of each attribute.

The total AHP score obtained for each alternative represents its relative value with respect to all attributes in the hierarchy.

\subsubsection{Consistency Ratio Check}

Consistency check has been developed to guarantee proper implementation of the pair-wise check comparison. For instance, let us consider that $\mathrm{x}$ is more important than $\mathrm{y}$ by factor of two and $\mathrm{y}$ is more important than $\mathrm{z}$ by factor of three then $\mathrm{x}$ should be six times z. Based on numerous empirical studies, it is acceptable to have inconsistency with a Consistency Ratio (CR) of $10 \%$ or less [10]. The consistency is checked using the following equations.

$$
\begin{aligned}
& C R=\frac{C I}{R I} \\
& C I=\frac{\lambda_{\max -n}}{n-1}
\end{aligned}
$$

Where;

$\mathrm{CI}$ is the consistency index.

$\lambda_{\max }$ : denotes the maximum principal eigenvalue of the comparison matrix.

RI: is random indices, as identified in Table 3.

$\mathrm{N}$ : is the matrix size.

To calculate $\lambda_{\max }$, the weighted sum vector (W') is calculated by multiplying pair-wise comparison (A) by the priority vector $(\mathrm{W})$. After that, the consistency vector (W') is calculated by dividing each element in $\mathrm{W}^{\prime}$ by its corresponding element in $\mathrm{W}$, as per the equations below:

$$
\begin{aligned}
& \mathrm{W}^{\prime}=\mathrm{W}^{*} \mathrm{~A} \\
& \lambda_{\max }=\frac{\sum_{i=1}^{n} W^{\prime \prime}}{n}
\end{aligned}
$$

Table 3: Random Index (Saaty, 1980)

\section{Trenchless Technology Module}

This module provides the suggested appropriate method or methods to the user that suits the project. In addition, data validation rules have been introduced to guarantee both logical data and reliable output. Figures 3 and 4 show screenshots from the interface showing the project attributes, defined in cases 1 and 2 in the respectively in the following sections and their selected trenchless method. 


\section{Model Validation}

AHP-DSS model was tested by comparing the results obtained from the model and the actual decisions made, based on past projects. Twenty different projects were selected and used for validation, the results obtained indicates that the percentage error was not exceeding 5\%. Two cases were selected to be discussed in details while the rest will be summarized in table 6 .

\subsection{Case Study 1}

The first case was "Metro line crossing - New Cairo pipeline". This project involved the construction of two shafts (jacking and receiving) with $14 \mathrm{~m}$ depth and the installation of $2 \times 3200 \mathrm{~mm}$ reinforced concrete pipes for a driving length of $80 \mathrm{~m}$ under a metro line, as a part of the New Cairo pipeline project. This project aimed to discharge $500,000 \mathrm{~m} 3 /$ day of potable water to the New Cairo water treatment plant. The crossing was in an urban congested area near the Nile corniche where; the intake is located. In addition, the ground water table level was high. The pipes are almost under the piers and therefore high accuracy during installation is required. Table 4 summarizes the input data for the model.

Table 4: Summary data for case 1- Metro line crossing New Cairo pipeline

\begin{tabular}{l|l}
\hline Parameters & Condition \\
\hline Project type & Crossing \\
Soil condition & Medium Sand \\
Depth of Installation & $14.0 \mathrm{~m}$ \\
Driving length & $80 \mathrm{~m}$ \\
Pipe diameter & $3200 \mathrm{~mm}$ \\
Pipe material & RCP \\
Utility installed & Pressurized flow \\
Boulders (if any) & No \\
Social consideration & High \\
Environmental consideration & Not mentioned (low) \\
GWT & $7 \mathrm{~m}$ \\
Accuracy required & $+/-50 \mathrm{~mm}$ \\
& \\
\hline
\end{tabular}

The AHP-DSS chose the "Slurry Microtunneling", which matched the actual construction method used by the contractor, accountable for this project, as shown in figure 3

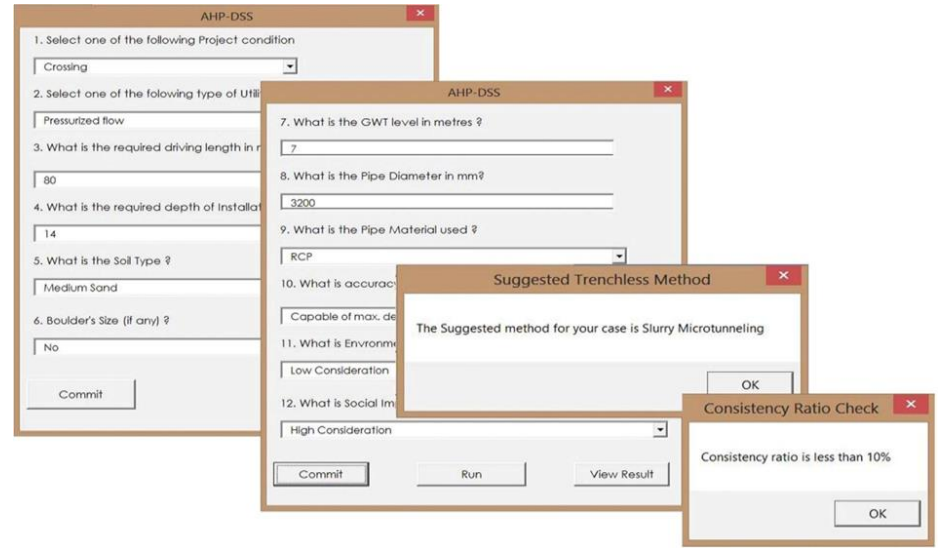

Figure 3: AHP-DSS results for Case 1 - Metro line crossing New Cairo pipeline

\subsection{Case Study 2}

The second case was "Gas-line project in Zionsville, IN" which was retrieved from (Abraham et al [11]). This project included the installation of a gas pipeline of $100 \mathrm{~mm}$ diameter in Zionsville, Indiana. The total driving length for this project was $1,470 \mathrm{~m}$ and one of the drives included the installation of $87 \mathrm{~m}$ of pipeline. The average depth of installation was $1.1 \mathrm{~m}$. The soil type was dry sand and the pipe material used was HDPE Nothing was mentioned about the social or environmental impact consideration or accuracy thus it would be assumed accordingly. Table 5 summarizes the input data for the model. The AHP-DSS chose the "Mini HDD", which matched the actual project construction method as shown in figure 4.

Table 5: Summary data for case 2 - Gas-line project in Zionsville,

\begin{tabular}{l|l}
\hline \multicolumn{1}{c|}{ Parameters } & \multicolumn{1}{c}{ Condition } \\
\hline Project type & Crossing \\
Soil condition & Medium Sand \\
Depth of Installation & $1.1 \mathrm{~m}$ \\
Driving length & $87 \mathrm{~m}$ \\
Pipe diameter & $100 \mathrm{~mm}$ \\
Pipe material & HDPE \\
Utility installed & Gas pipeline \\
Boulders (if any) & No \\
Social consideration & Not mentioned \\
Environmental consideration & Not mentioned \\
GWT & 0 \\
Accuracy required & Not mentioned \\
\hline
\end{tabular}




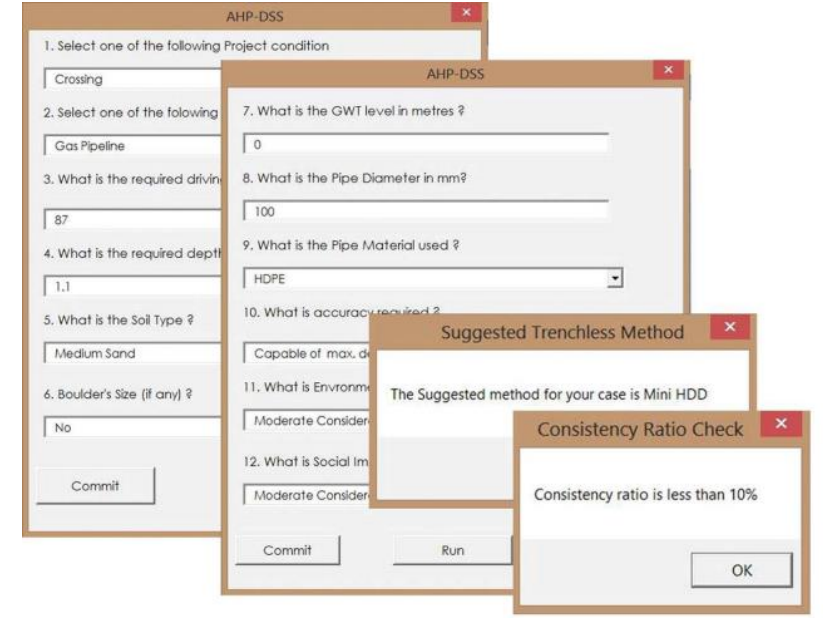

Figure 4: AHP-DSS results for case 2 - Gas-line project in Zionsville, IN
The following table summarizes the results obtained from the model for the remaining cases and the actual method used and selected to be implemented. The AHP-DSS in one case provided a different solution from the actual method used (Case 12). The model selected the Horizontal Auger Boring while the contractor used Pipe Ramming. The difference was due to the soil type "stiff clay", according to the experts Horizontal Auger Boring is able to work in stiff clay while Pipe Ramming is possible to work in it. The model gave the auger boring higher score than the Pipe Ramming and that is why Horizontal Auger Boring was selected. Both methods got the same scores for the remaining attributes.

Table 6: AHP-DSS Results

\begin{tabular}{|c|c|c|c|c|c|c|c|c|c|c|c|c|c|c|}
\hline Cases & $\begin{array}{l}\text { Project } \\
\text { Type }\end{array}$ & $\begin{array}{l}\text { Diameter } \\
/ \mathrm{mm}\end{array}$ & Depth/m & Soil type & $\begin{array}{l}\text { Pipe } \\
\text { material }\end{array}$ & Utility Installed & Social & Environmental & Accuracy required & Boulders & Length & GWT/m & $\begin{array}{l}\text { AHP-DSS } \\
\text { Output }\end{array}$ & Actual method \\
\hline Case 1 & Crossing & 900 & 3 & Med.Sand & Steel & Pressure & Low & Low & Limited steering & No & 23 & 0 & $\mathrm{HAB}^{*}$ & HAB \\
\hline Case 2 & Crossing & 100 & 1.1 & Dense Sand & HDPE & Gas & Low & Low & $(+/-100 \mathrm{~mm})$ & No & 87 & 0 & Mini HDD & Mini HDD \\
\hline Case 3 & Crossing & 1000 & 6 & Firm Clay & GRP & Gravity Sewer & Low & Low & $(+/-100 \mathrm{~mm})$ & No & 120 & 0 & Slurry MT* & Slurry MT \\
\hline Case 4 & Crossing & 600 & 6 & Med.Sand & VCP & Gravity Sewer & Low & Low & $(+/-100 \mathrm{~mm})$ & No & 122 & 4.5 & Slurry MT & Slurry MT \\
\hline Case 5 & Crossing & 750 & 3.2 & Firm Clay & Steel & Pressure & Low & Low & Limited steering & No & 18 & 0 & Pipe Ramming & Pipe Ramming \\
\hline Case 6 & Crossing & 1300 & 7 & Loose Sand & GRP & Gravity Sewer & High & Low & $(+/-100 \mathrm{~mm})$ & No & 200 & 1.5 & Slurry MT & Slurry MT \\
\hline Case 7 & Crossing & 112 & 3.1 & Firm Clay & HDPE & Gas & Mod $^{*}$ & Low & $(+/-100 \mathrm{~mm})$ & $<1 / 3 \mathrm{D}$ & 87 & 0 & Mini HDD & Mini HDD \\
\hline Case 8 & Crossing & 3200 & 14 & Medium Sand & RCP & Pressure & High & Low & $(+/-50 \mathrm{~mm})$ & $<1 / 3 \mathrm{D}$ & 80 & 7 & Slurry MCT & Slurry MCT \\
\hline Case 9 & Non-Crossing & 1200 & 4 & Gravel & GRP & Gravity & Low & Low & $(+/-100 \mathrm{~mm})$ & No & 6 & 0 & Open Cut & Open Cut \\
\hline Case 10 & Crossing & 3000 & 7 & Dense Sand & RCP & Pressure & Low & Low & $(+/-100 \mathrm{~mm})$ & No & 24 & 0 & Open face TBM & Open face TBM \\
\hline Case 11 & Crossing & 1200 & 3 & Gravel & Steel & Pressure & Low & Low & Limited Steering & No & 60 & 0 & Pipe Ramming & Pipe Ramming \\
\hline Case 12 & Crossing & 800 & 5.4 & Stiff Clay & Steel & Pressure & Low & Low & Limited Steering & No & 50 & 0 & HAB & Pipe Ramming \\
\hline Case 13 & Crossing & 3000 & 15 & Stiff Clay & RCP & Pressure & Low & Low & $(+/-100 \mathrm{~mm})$ & No & 65 & 2 & EPB MT & EPB MT \\
\hline Case 14 & Crossing & 1000 & 10 & Medium Sand & HDPE & Gravity & Low & Low & $(+/-100 \mathrm{~mm})$ & No & 270 & 0 & Maxi-HDD & Maxi HDD \\
\hline Case 15 & Crossing & 800 & 8 & Stiff Clay & VCP & Gravity & Med & Med & $(+/-100 \mathrm{~mm})$ & No & 150 & 2 & EPB or Slurry MT & Slurry MT \\
\hline Case 16 & Crossing & 1100 & 3.2 & Soft Clay & Steel & Pressure & Mod & Mod & Limited Steering & $\angle 1 / 3 \mathrm{D}$ & 45 & 2 & $\mathrm{HAB}$ & HAB \\
\hline Case 17 & Non-Crossing & 900 & 2 & Gravel & HDPE & Cables & Low & Low & $(+/-100 \mathrm{~mm})$ & No & 20 & 3 & Open Cut & Open Cut \\
\hline Case 18 & Crossing & 1200 & 10 & Soft Clay & Steel & Gravity & Low & Low & $(+/-100 \mathrm{~mm})$ & No & 210 & 4 & Maxi-HDD & Maxi HDD \\
\hline Case 19 & Crossing & 150 & 4 & Sand-stone & HDPE & Cables & Low & Low & $(+/-100 \mathrm{~mm})$ & No & 25 & 0 & Mini- HDD & Mini HDD \\
\hline Case 20 & Crossing & 3200 & 20 & Medium Sand & $\mathrm{RCP}$ & Pressure & High & Low & $(+/-50 \mathrm{~mm})$ & No & 30 & 4 & Slurry MT & Slurry MT \\
\hline
\end{tabular}

*HAB: Horizontal Auger Boring, MT*: Microtunneling and Mod*: Moderate 


\section{Analysis \& Discussion}

For the first case "Metro line - New Cairo pipeline", the AHP-DSS output was identical to the actual construction method implemented by the contractor (i.e. slurry microtunneling, which seems to be the most suitable method). Accordingly, the second best method after the slurry microtunneling was the pipe jacking open face TBM, which has satisfied all the project attributes and parameters except the GWT as it was high beyond its capabilities. As shown in figure 5, the highest weights were assigned to the project type, pipe diameter and GWT. Hence, as it was a crossing project in a congested area, open cut was excluded. Additionally, the trenchless methods that can satisfy a $3.2 \mathrm{~m}$ reinforced concrete pipe diameter are limited to the open cut (excluded due to the project type), pipe jacking open face TBM and slurry microtunneling. Finally, the $7.0 \mathrm{~m} \mathrm{GWT}$ is limited to work with slurry microtunneling, open cut (excluded due to the project type) and HDD (excluded due to insufficiency for the pipe diameter). Therefore, project type, GWT and pipe diameter were assigned the highest weights since they were satisfied by few number of methods for this case.

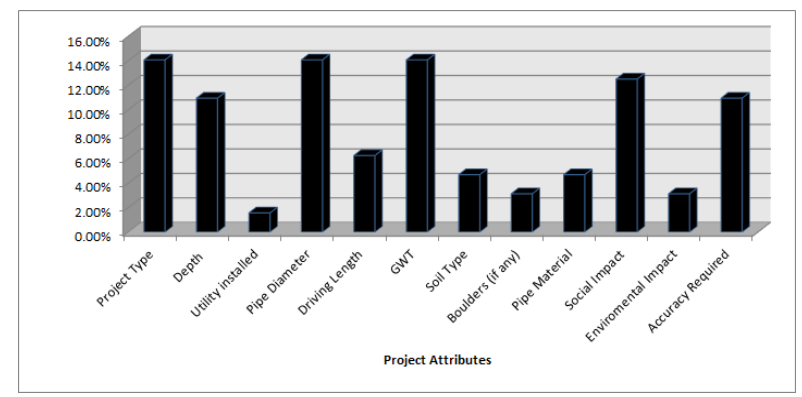

Figure 5: Attributes weights for case 1 - Metro line crossing - New Cairo pipeline

Regarding the second case "Gas-line project in Zionsville, IN", the AHP-DSS output was identical to the actual trenchless construction method, (i.e. MiniHDD). As shown in figure 6, the governing attributes that gained the highest weights were project type, and pipe diameter. Hence, as it was a crossing project, open cut was excluded. Then, the $0.9 \mathrm{~m}$ pipe diameter can only work with pipe ramming, open cut (excluded due to the project type) and Mini HDD. Finally, the HDPE pipe material can only work with Mini HDD, open cut (excluded due to the project type). Since, few numbers of methods satisfied these attributes, they gained higher weights compared to the others. Therefore, Mini HDD was chosen, based on the below weights defined in figure 6 , as the most suitable construction method for this project.

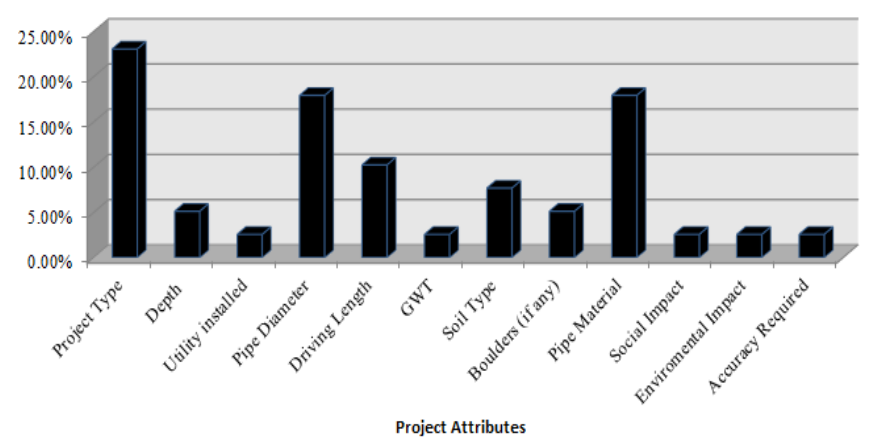

Figure 6: Attributes weights for case 2 - Gas-line project in Zionsville, IN

\section{Concluding Remarks}

The trenchless technology methods are more favourable compared to the open-cut method in urban areas. Due to the variety of trenchless methods, it was crucial to present a DSS that selects the most appropriate construction method that fits the project attributes and surrounding conditions. The proposed model was built using an AHP engine, incorporating wide spectrum of parameters to provide precise decisions for the construction method. Further work is required to include a cost estimation module, which incorporates the cost as a key attribute in deciding on the construction method, after being technically accepted by the existing AHP-DSS.

Some other parameters can be considered for future research that include safety and health issues that could affect the selection of different trenchless methods.

\section{Acknowledgment}

Special acknowledgement to Mr. Nabil Abdel Salam, the project manager of New-Cairo pipeline project, and Mr. Ahmed Abo Deshish, the head of tunnelling department in Arab Contractors; for their provision of data and insightful contributions in performing the AHP-DSS model.

\section{References}

[1] Ariaratnam, S. T., Member, A., Asce, A., Lueke, J. S., and Allouche, E. N. Utilization of Trenchless Construction Methods by Canadian Municipalities. Journal of Construction Engineering and Management, 125(2), 76, 1999.

[2 Pau, S. H., Chau, K. W., and Wong, W. G. Prospects for No-Dig Technology in Hong Kong Construction Industry. Journal of Construction 
Engineering and Management, 119(3), 550, 1993.

[3] Ariaratnam, S. T., Piratla, K., Cohen, A., and Olson, M. Quantification of Sustainability Index for Underground Utility Infrastructure Projects. Journal of Construction Engineering and Management, 139(12), A4013002, 2013.

[4] Gokhale, S., and Hastak, M. Decision aids for the selection of installation technology for underground municipal infrastructure systems. Tunnelling and Underground Space Technology, $15,1-11,2000$.

[5] Ueki, M., Haas, C. T., and Seo, J. Decision Tool for Microtunneling Method Selection. Journal of Construction Engineering and Management, 125(2), 123, 1999.

[6] Baik, H., Abraham, D., and Gokhale, S. A decision support system for horizontal directional drilling. Tunnelling and Underground Space Technology, 99-109, 2003.

[7] Chung, T. H., Abraham, D. M., and Gokhale, S. B. Decision Support System For Microtunneling Applications. Journal of Construction Engineering and Management, 130(6), 835, 2004.

[8] Bottero, M., and Peila, D. The use of the Analytic Hierarchy Process for the comparison between microtunneling and trench excavation. Tunnelling and Underground Space Technology, 20(6), 501513,2005

[9] Allouche, e. (n.d.). A decision-support model for selection of a trenchless construction method, 2001.

[10] Saaty, T. L. The analytic hierarchy process: planning, priority setting, resource allocation. New York: McGraw-Hill International Book Co, 1980.

[11] Abraham, D., Baik, H., Gokhale, S. Development of a Decision Support System for Selection of Trenchless Technologies to Minimize Impact of Utility Construction on Roadways. Joint Research Study, School of Civil Engineering, Purdue University, West Lafayette, Indiana, 2002. 